in grasping these basic ideas from other sources, he should be able to proceed readily with the rest of the book. It is, perhaps, unfortunate that some of the theories of reaction rates are not introduced earlier than Chapter 9, so that the ideas developed there could be used en route.

Finally, I must introduce what is perhaps a more personal note, although I am sure that others also involved with kinetics in solution will echo my view. Most general books on kinetics concentrate on the gas phase; understandably so, as here individual molecular processes can be examined in detail. Yet rarely are the complexities of processes in solution dismissed so completely: these are merely referred to very briefly in one paragraph in Chapter 5 .

Although I have obviously read this book with a critical eye, I realize, of course, that not everything can be included in a book of this size. Moreover, I am sure that all who are interested in kinetics will find it stimulating, and this includes undergraduates. It certainly should find a place on library shelves. The format of the book is good and it is well produced; the price is not unreasonable for these days.

C.F. Wells is Reader in Inorganic Chemistry at the University of Birmingham, UK, and has particular interest in the kinetics of inorganic reactions in solution.

\section{Volcanoes revisited}

\section{P.E. Baker}

Volcanology. By H. Williams and A. R. McBirney. Pp.397. (Freeman, Cooper \& Co.: San Francisco; Blackwell Scientific: Oxford, 1979.) $£ 19.50, \$ 33.50$.

THE authors preface their book with the modest statement that it "... does not purport to offer much that is new; it attempts rather, to summarize for the student and professional geologist current knowledge of volcanoes, particularly their behaviour and physical structure". Despite a superficial resemblance to earlier books on the subject of volcanoes (for example, Macdonald, 1972) and some fairly conventional chapter headings, the approach is essentially rather different. It is a textbook aimed at a specialist readership and largely devoid of dramatic accounts of volcanic eruptions and their consequences. It is written in a lucid and cautious style with every effort being made to adopt a quantitative approach. It attempts a rigorous explanation of volcanic processes and products in terms of established physical principles. There are more descriptive chapters, such as those on "Principal kinds of eruptions" and "Cones, domes and shields", which contain innumerable examples drawn from the authors' wide experience.

They pick their way delicately through the subject, rejecting untenable generalizations and sometimes reconsidering discarded theories. They remind us that the evidence for extraordinary amounts of igneous activity along the axes of oceanic ridge crests is largely circumstantial, and that potassium does not invariably increase towards the interior of continents. Perhaps, also, there is some truth in Daly's theory of the 'vitreous substratum' source for basalt.

At the end of the opening chapter the authors state that, "By far the greatest impetus for studies of igneous processes has come from a growing recognition of the central role they play in nearly all modern tectonic theories". Maps of active volcanoes and plate boundaries appear on the inside covers of the book but can scarcely be regarded as reflecting the

dominant theme of the text. There are references to sea-floor spreading, midplate volcanism and subduction of oceanic lithosphere, but the authors appear anxious not to overemphasize the link between volcanism and plate tectonics.

The scope of the book has been carefully restricted and there is, for example, very little discussion of the role of volcanism in the evolution of the Earth, or of volcanism and mineralization. Volcanic activity in the rest of the Solar System is also excluded apart from occasional references and photographs of the martian volcano Olympus Mons and a NASA picture of

\section{Methods for studying evolution}

\section{R.A. Fisher}

Biochemical Systematics and Evolution. By A. Ferguson. Pp.194. (Blackie: Glasgow, 1979.) £14.50.

THE popular image of a taxonomist is of a cantankerous anatomist interminably arguing with an equally cantankerous opponent over some apparently trivial detail. These days, it seems, anatomists are out and biochemical geneticists are in. Cantankerousness and argument are, of course, always with us, but perhaps for those who wish to understand rather than stake their reputations, biochemical systematics can throw some new and useful light on the processes of evolution.

Evolution depends on mutations in DNA, and the basic idea behind biochemical taxonomy is to detect the mutations themselves rather than their effects at several removes. Events overtake us with distressing rapidity these days and it is unfortunate for Dr Ferguson in his book Biochemical Systematics and Evolution that he missed the opportunity of mentioning the new technique of restriction mapping, since this allows one to examine the actual gene at first hand. But it is neither the easiest nor the cheapest of methods and for some time to come the electrophoretic comparison of proteins will certainly remain the method of convenience, if not of choice. It involves the volcanic activity on Io.

The book is generously illustrated with many first-class photographs and the occasional indifferent one (for example, Fig. 7-11). The figures are drawn in somewhat varied styles but are not always to the standard one might have expected. Nevertheless, in its description and interpretation of volcanic phenomena this is an excellent book and the authors have certainly succeeded in the task they set themselves.

P. E. Baker is Professor of Geology at the University of Nottingham, UK.

investigation of the gene product rather than the gene, but it is much closer to the ideal than the morphometric comparisons of anatomists.

Electrophoresis is a well established and well described technique and much has been published on the interpretation of protein separations and zymograms. It is a pity, therefore, that, having stated that the aim of this book "is to provide the reader with the necessary background to the principles and practice of electrophoresis", the author does not make a better job of it. If this really was his aim, the sections on methods are too brief and in parts misleading. If one were, for example, to try electrophoresis according to the diagram on page 36 , one would fail. Electrical contact between the gel and the electrodes is apparently prevented by a plastic film. The chapter which deals with the interpretation of isozyme patterns is again too brief and sometimes inaccurate. In particular, the origins of isozymes could have been more clearly explained.

The second half of the book deals with the interpretation of data, and here $\mathrm{Dr}$ Ferguson seems to be on much more familiar territory. He deals concisely and clearly with the various ways of measuring evolutionary distance and the mathematical examples are well explained and easy to follow. It is this part of the book that will really be of use to the audience for which it is intended, "advanced undergraduate and postgraduate students".

R.A. Fisher is Head of the Comparative Genetics Section in the Nuffield Laboratories of Comparative Medicine at the London Zoo, UK. 